\title{
Estudos sobre prisão: um balanço do estado da arte nas ciências sociais nos últimos vinte anos no Brasil (1997-2017)
}

\author{
Luiz Claudio Lourenço ${ }^{1}$
}

Marcos César Alvarez ${ }^{2}$

\section{Punição e prisão na agenda de pesquisa nas ciências sociais}

Os estudos sobre prisão nas ciências sociais estão enraizados em reflexôes e investigaçóes desenvolvidas na Europa e nos Estados Unidos a partir de meados do século XIX, momento em que a própria instituição prisional ganha destaque nos sistemas punitivos modernos.

No âmbito da sociologia, desde os clássicos, o interesse pela punição em geral se desdobrou em estudos específicos também sobre a prisão e seus efeitos na vida social. Por um lado, a trilha aberta por Émile Durkheim, no sentido de uma sociologia da punição, que associava as formas punitivas às formas sociais mais gerais, foi seguida, já no século XX, tanto por estudos de inspiração marxista - como o trabalho de Georg Rusche e Otto Kirchheimer, Punição e Estrutura Social (RUSCHE; KIRCHHEIMER, 2004), publicado originalmente em 1939, que relacionava regimes punitivos e sistemas de produção - quanto por estudos como Vigiar e Punir (FOUCAULT, 1977), que abordava as práticas punitivas como mecanismos complexos de poder. Por outro lado, desenvolveu-se uma tradição de investigação, sobretudo em língua inglesa, voltada para: o estudo da especificidade das instituiçôes prisionais, como The Prison Community de Donald Clemmer, publicado em 1940, The Society of Captives de Gresham Sykes, publicado em 1958, ou The Discovery of Asylum, escrito por David Rothman e publicado em 1971; ou ainda, para as especificidades das chamadas instituiçóes totais, caminho explorado por Asylums, de Erving Goffman, publicado em 1961 (CLEMMER, 1958; GOFFMAN, 1961; ROTHMAN, 1990; SYKES, 1974).

No Brasil, inicialmente, o tema foi mais discutido nos campos do direito e da medicina. Mesmo com a criação de cursos de ciências sociais no país, a partir dos anos 1930, a situação permaneceu inalterada por longo tempo (SALLA, 2006). Trabalhos pioneiros de juristas como Antonio Herculano Bandeira Filho, de 1881, e Lemos Brito, de 1924, foram acompanhados por observaçóes e reflexóes também de médicos envolvidos com as escolas criminológicas da época (ALVAREZ, 2003). Assim, será apenas a partir de 1970, com o processo de redemocratização no país e a crescente preocupação com as violaçóes dos Direitos Humanos

1 Possui bacharelado e mestrado em ciências sociais pela Universidade de São Carlos (UFSCar), doutorado em ciência política pelo Instituto Universitário de Pesquisas do Estado do Rio de Janeiro (Iuperj) e pós-doutorado em sociologia pela Universidade de São Paulo (USP). Atualmente é professor do Departamento de Sociologia e pesquisador no Laboratório de Estudos sobre Crime e Sociedade (Lassos) da Universidade Federal da Bahia (UFBA). E-mail: lulalourenco@gmail.com

2 Bacharel em ciências sociais pela Universidade de São Paulo (USP), mestre e doutor em sociologia pela mesma instituição. Atualmente é professor Livre Docente do Departamento de sociologia da USP, pesquisador do Núcleo de Estudos da Violência, NEV-USP, bolsista do CNPq, nível 1C, e pesquisador principal do projeto temático "A gestáo do conflito na produção da cidade contemporânea: a experiência paulista”, financiado pela Fapesp. E-mail: mcalvarez@usp.br 
perpetradas num sistema prisional precário e violento, que passam a se avolumar contribuiçôes acadêmicas nas ciências sociais baseadas em pesquisas empíricas e não apenas no debate doutrinário. Trabalhos pioneiros como o de José Ricardo Ramalho, de 1979, sobre a Casa de Detenção em São Paulo, e o de Julita Lemgruber, realizado em 1976, mas publicado em 1983, sobre a Penitenciária Talavera Bruce no Rio de Janeiro, começam a demarcar um campo específico de investigaçóes.

Essa produção irá se expandir significativamente a partir da virada do século. Diversificam-se as instituiçóes pesquisadas, agora também em outros estados que não apenas São Paulo e Rio de Janeiro, bem como os diálogos com a literatura internacional e suas diferentes perspectivas, tanto dos estudos prisionais stricto sensu quanto de autores como Goffman, com sua reflexão sobre as "instituiçóes totais", de Foucault, sobre os mecanismos de poder ${ }^{3}$, David Garland, sobre a punição contemporânea (GARLAND, 2008), e muitos outros. Além disso, verifica-se um entrecruzamento das diferentes ciências sociais, antropologia, ciência política e sociologia.

Nas últimas duas décadas, a literatura sobre prisóes em nosso país tem crescido expressivamente em várias áreas do conhecimento, inclusive nas ciências sociais. A punição como tema mais geral passou a ingressar como parte da agenda de pesquisa de inúmeros grupos e programas de pós-graduaçáo e igualmente os estudos sobre prisóes e instituiçôes correlatas.

Alguns textos que trataram de mapear os estudos sobre crime e violência na produção brasileira já identificaram contribuiçôes importantes realizadas na área dos estudos prisionais (ADORNO, 1993; CAMPOS; ALVAREZ, 2017; MISSE; LIMA; MIRANDA, 2000;
ZALUAR, 1999). Mais recentemente, revisóes mais específicas têm sido produzidas, como os casos de Salla (2006) e de Lourenço (2016), que fazem apanhados das pesquisas pioneiras no estudo de prisóes realizadas durante os anos 1970 e 1980 no país; além de Teixeira e Oliveira (2016), que mapearam o que foi produzido acerca de maternidade e encarceramento feminino no Brasil.

Contudo, lacunas importantes ainda podem ser preenchidas, como o mapeamento das dissertaçóes e das teses que vêm sendo produzidas sobre prisóes no país no âmbito das ciências sociais nos últimos vinte anos (1997-2017), um trabalho iniciado por Salla, em sua revisão publicada em 2006, e que é aprofundada neste texto.

\section{A pesquisa em teses e dissertações: objetivo e metodologia empregada}

Como afirmado, o principal objetivo aqui consiste justamente em levantar e discutir as características gerais das teses e das dissertaçóes produzidas e disponíveis nos repositórios institucionais dos programas de pós-graduação em sociologia, antropologia, ciência política e ciências sociais no período de 1997 a 2017.

Para realizar esta pesquisa, inicialmente foram escolhidas palavras-chave para serem inseridas nas buscas em repositórios on-line. As palavras selecionadas foram as seguintes: encarceramento, prisóes, cárcere, sistema prisional, estudos prisionais, presídio, penitenciária, unidade(s) prisional(is), hospital(is) de custódia, HCT, manicômio(s) judiciário(s), agente(s) penitenciário(s), gestor(es) prisional(is), facçôes, gangues prisionais, comandos, apenados, sentenciados, presos, internos, presidiário(s), privação de liberdade, reeducando(s), ressocialização, reabilitação, reeducação.

3 Sobre o impacto de Vigiar e Punir nos estudos prisionais no Brasil, consultar Salla (2017). 
Nossa primeira opção foi realizar a pesquisa no portal da Biblioteca Digital Brasileira de Teses e Dissertaçóes - BDTD ${ }^{4}$. Contudo, após algumas buscas iniciais, verificamos que nem todos os programas das áreas que compreendem as ciências sociais disponibilizam suas produçóes na BDTD. Isso nos obrigou a listar os programas avaliados pela Capes nas áreas de sociologia, antropologia e ciência política e investigar um a um em seus próprios repositórios institucionais. Foi pesquisado um total de 56 repositórios institucionais.

O primeiro resultado relevante do levantamento foi a constatação de expressiva produção encontrada: 139 trabalhos, sendo 93 dissertaçóes e 46 teses. Esse dado é importante, pois mostra como o tema das prisóes entrou na agenda de pesquisa de mestrandos e doutorandos no período. Além disso, verificamos que em 38 dos 56 repositórios $(67,9 \%)$ foram encontradas teses e/ou dissertaçóes com os termos de busca utilizados. Ou seja, na maioria dos programas de pós-graduação em ciências sociais, foram produzidas pesquisas na área.

Observando a distribuição regional do total de teses e de dissertaçóes, também percebemos que, embora uma parte importante da produção esteja na região Sudeste $(48,9 \%)$, já há uma expressiva produção no Nordeste (24,5\%), sendo que nenhuma regiâo do país deixou de produzir estudos sobre prisóes no período (Tabela 1). Desse modo, podemos afirmar igualmente que já há uma produção nacional na temática, embora ainda com grandes diferenças regionais.

Discriminando a produção por regióes, notamos que a distribuição das dissertações é mais diversificada, e a de teses mais, concentrada regionalmente (Tabela 2 ), o que provavelmente acompanha a concentraçáo dos doutorados na rede de pós-graduação das ciências sociais.
Tabela 1

Distribuição da produção total por região do país (1997-2017)

\begin{tabular}{lcc}
\hline & n & \% \\
\hline Sudeste & 68 & 48,9 \\
\hline Nordeste & 34 & 24,5 \\
\hline Sul & 25 & 18 \\
\hline Centro-Oeste & 6 & 4,3 \\
\hline Norte & 6 & 4,3 \\
\hline Total & 139 & 100 \\
\hline
\end{tabular}

Fonte: Elaboração própria.

Tabela 2

Distribuição teses e dissertações por região

\begin{tabular}{llcc}
\hline \multirow{4}{*}{ Dissertaçōes } & & n & \% \\
\hline & Sudeste & 43 & 46,2 \\
\cline { 2 - 4 } & Nordeste & 25 & 26,9 \\
\cline { 2 - 4 } & Sul & 21 & 22,6 \\
\cline { 2 - 4 } & Norte & 3 & 3,2 \\
\cline { 2 - 4 } & Centro-Oeste & 1 & 1,1 \\
\cline { 2 - 4 } Teses & Total & 93 & 100 \\
\hline \multirow{4}{*}{} & Sudeste & 25 & 54,3 \\
\cline { 2 - 4 } & Nordeste & 9 & 19,6 \\
\cline { 2 - 4 } & Centro-Oeste & 5 & 10,9 \\
\cline { 2 - 4 } & Sul & 4 & 8,7 \\
\cline { 2 - 4 } & Norte & 3 & 6,5 \\
\cline { 2 - 4 } & Total & 46 & 100 \\
\hline
\end{tabular}

Fonte: Elaboração própria.

No que se refere ao volume de trabalhos por período, constatamos um incremento significativo recentemente, já que a média nos primeiros cinco anos (1997-2001) não chegou a contar um trabalho por ano e que nos últimos cinco anos (2013-2017), a média anual foi de 11,6 trabalhos por ano (Tabela 3 e Figura 1).

4 Disponível em: <http://bdtd.ibict.br/vufind >. 
Tabela 3

Teses e dissertações sobre prisão e punição no período (1997-2017)

\begin{tabular}{cccc}
\hline & Dissertaçóes & Teses & Total \\
\hline 1997 & 1 & 0 & 1 \\
\hline 2000 & 1 & 0 & 1 \\
\hline 2002 & 3 & 0 & 3 \\
\hline 2004 & 3 & 0 & 3 \\
\hline 2005 & 6 & 1 & 7 \\
\hline 2006 & 3 & 4 & 7 \\
\hline 2007 & 4 & 3 & 7 \\
\hline 2008 & 7 & 1 & 8 \\
\hline 2009 & 6 & 1 & 7 \\
\hline 2010 & 8 & 4 & 12 \\
\hline 2011 & 3 & 8 & 11 \\
\hline 2012 & 8 & 5 & 13 \\
\hline 2013 & 11 & 2 & 13 \\
\hline 2014 & 8 & 4 & 12 \\
\hline 2015 & 7 & 5 & 14 \\
\hline 2016 & 8 & 6 & 8 \\
\hline 2017 & 6 & 2 & 139 \\
\hline Total & 93 & 46 & \\
\hline
\end{tabular}

Fonte: Elaboraçáo própria.

Figura 1

Distribuição temporal da produção de dissertações e teses no campo de estudos sobre prisões no Brasil (1997-2017)

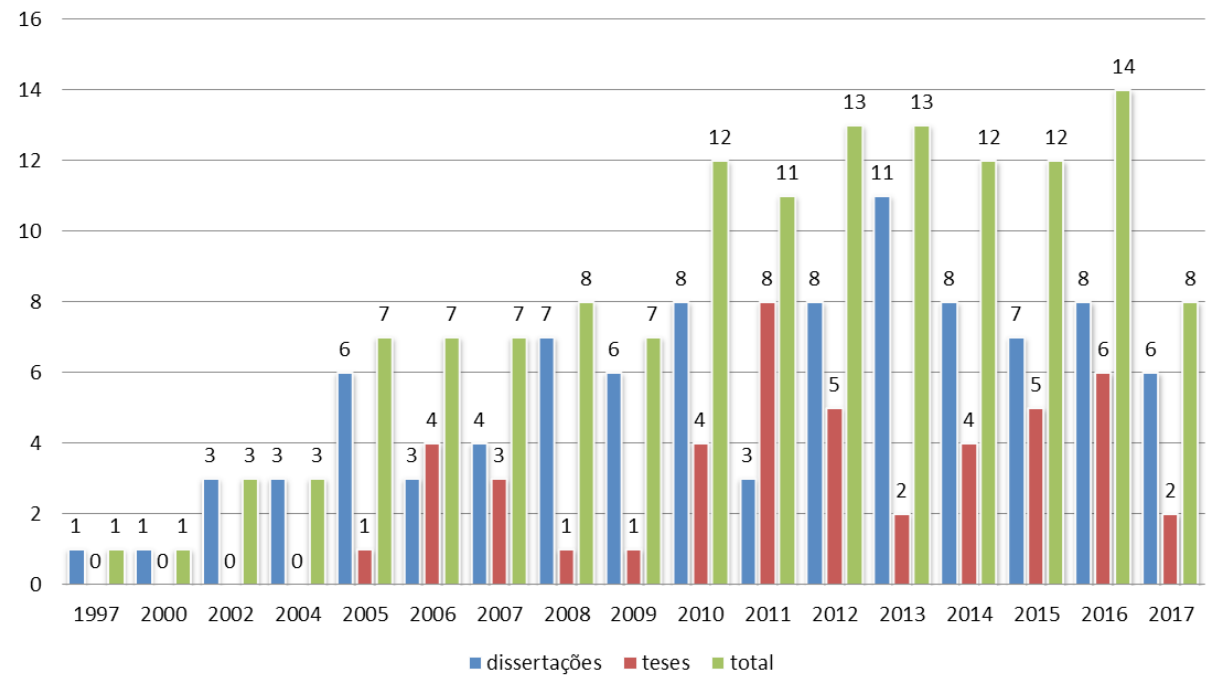

Fonte: Elaboração própria. 
No que diz respeito à distribuição por área de conhecimento, observamos que os programas de pós-graduação em sociologia foram os que concentraram o maior número de trabalhos, tanto em dissertaçóes $(41,9 \%)$ quanto em teses (50\%). Esse dado é um indício importante do desenvolvimento do campo de estudos prisionais e da sociologia da punição dentro da sociologia brasileira. Por outro lado, a ciência política foi uma das áreas com menor concentração de trabalhos, o que demonstra que há um grande potencial de estudos a serem desenvolvidos com suporte teórico e abordagens nesse campo das ciências sociais (Tabela 4), sobretudo no que diz respeito às políticas prisionais, como retomaremos posteriormente.

\section{Tabela 4}

Distribuição por áreas dos programas de pós-graduação

\begin{tabular}{lcccc}
\hline \multicolumn{1}{c}{$\begin{array}{c}\text { Área do } \\
\text { programa }\end{array}$} & \multicolumn{2}{c}{ Dissertaçóes } & \multicolumn{2}{c}{ Teses } \\
\cline { 2 - 5 } $\begin{array}{l}\text { Antropologia } \\
\text { e sociologia }\end{array}$ & 2 & 2,2 & 2 & 4,3 \\
\hline Antropologia social & 12 & 12,9 & 7 & 15,2 \\
\hline Ciência política & 8 & 8,6 & 2 & 4,3 \\
\hline Ciências humanas & 2 & 2,2 & 1 & 2,2 \\
\hline Ciências sociais & 30 & 32,3 & 11 & 23,9 \\
\hline Sociologia & 39 & 41,9 & 23 & 50 \\
\hline Total & 93 & 100 & 46 & 100 \\
\hline
\end{tabular}

Fonte: Elaboração própria.

Conforme Tabela 5, do total das dissertaçôes produzidas no período, destaca-se o papel formador das seguintes instituições: UFSCar (dez dissertaçôes, 10,8\%), UFBA (seis dissertaçôes, 6,5\%) e USP, UFRGS, PUC-RS, UEFN, UFPR, UFRJ, UNICAMP (todas com cinco dissertações, 5,4\%). Conjuntamente, essas instituiçôes acumulam 49,5\% das dissertaçóes no período. Já no que se refere às teses, a USP e a
UNB se destacam no período, com sete (15,2\%) e cinco $(10,9 \%)$ trabalhos, respectivamente.

Tabela 5

Teses e dissertações por instituição

\begin{tabular}{|c|c|c|}
\hline \multirow{2}{*}{ Instituiçấo } & \multicolumn{2}{|c|}{ Dissertaçóes } \\
\hline & $n$ & $\%$ \\
\hline UFSCar & 10 & 10,8 \\
\hline UFBA & 6 & 6,5 \\
\hline USP & 5 & 5,4 \\
\hline UFRGS & 5 & 5,4 \\
\hline PUC-RS & 5 & 5,4 \\
\hline UEFN & 5 & 5,4 \\
\hline UFPR & 5 & 5,4 \\
\hline UFRJ & 5 & 5,4 \\
\hline UFC & 4 & 4,3 \\
\hline UNESP-Mar & 4 & 4,3 \\
\hline UFJF & 4 & 4,3 \\
\hline UNICAMP & 3 & 3,2 \\
\hline UFAM & 3 & 3,2 \\
\hline UFS & 3 & 3,2 \\
\hline UFPE & 2 & 2,2 \\
\hline UFPB & 2 & 2,2 \\
\hline UFSC & 2 & 2,2 \\
\hline PUC-SP & 2 & 2,2 \\
\hline UECE & 2 & 2,2 \\
\hline UERJ & 2 & 2,2 \\
\hline UFAL & 2 & 2,2 \\
\hline UFES & 2 & 2,2 \\
\hline UNB & 1 & 1,1 \\
\hline PUC-MG & 1 & 1,1 \\
\hline UFRB & 1 & 1,1 \\
\hline UFSM & 1 & 1,1 \\
\hline UNIFESP & 1 & 1,1 \\
\hline UNISINOS & 1 & 1,1 \\
\hline UEL & 1 & 1,1 \\
\hline UEM & 1 & 1,1 \\
\hline UFCG & 1 & 1,1 \\
\hline UFMG & 1 & 1,1 \\
\hline Total & 93 & 100 \\
\hline
\end{tabular}


Tabela 5 - continuação

\begin{tabular}{llc}
\hline \multirow{2}{*}{ Instituiçáo } & \multicolumn{2}{c}{ Teses } \\
\cline { 2 - 3 } & $n$ & $\%$ \\
\hline USP & 7 & 15,2 \\
\hline UNB & 5 & 10,9 \\
\hline UNICAMP & 4 & 8,7 \\
\hline UFRGS & 4 & 8,7 \\
\hline UFPE & 4 & 8,7 \\
\hline UFSCar & 3 & 6,5 \\
\hline UFPB & 3 & 6,5 \\
\hline PUC-SP & 3 & 6,5 \\
\hline UERJ & 3 & 6,5 \\
\hline UFRJ & 3 & 6,5 \\
\hline UFPA & 2 & 4,3 \\
\hline UFC & 1 & 2,2 \\
\hline UNESP-MAR & 1 & 2,2 \\
\hline UFAM & 1 & 2,2 \\
\hline UFJF & 1 & 2,2 \\
\hline UNESP-AR & 1 & 2,2 \\
\hline Total & 46 & 100 \\
\hline
\end{tabular}

Fonte: Elaboração própria.

Para realizar uma análise mais substantiva, ainda que preliminar, dessa expressiva produção intelectual, recorremos à leitura dos resumos, ao buscar identificar os temas mais recorrentes. O Quadro 1 mostra alguns dos temas mais presentes no interior do banco de teses e de dissertaçôes construído.

Observamos que pesquisas que abordaram mulheres nas prisōes foram as mais frequentes, num total de 25 (18\%). Muitos dos trabalhos trataram de múltiplos aspectos referentes ao confinamento de mulheres (ALMEIDA, 2006; ANDRADE, 2015; CARDOSO, 2017; LAGO, 2014; MATSUDA, 2016; QUADRADO 2014; SANTOS, L. A., 2015). Por sua vez, encontramos trabalhos que se centraram em questóes mais específicas, dentre as quais se destacam: a prisão de mulheres por tráfico de drogas (FRANÇA, 2013; LIMA, 2016; MOURA, 2005; PEREIRA, 2008), mulheres egressas das prisôes (COSTA, 2011; REIF, 2016; SANTOS, F. C. M., 2016) e maternidade nas prisões (LOPES, 2014; MARTINS, 2016; QUINTINO, 2005). O papel reabilitador do cárcere, seja nas chamadas práticas de ressocializaçáo ou mesmo nas atividades de trabalho e educação realizadas no cárcere, foi abordado em quinze $(10,8 \%)$ trabalhos, sendo que parte dos estudos tenderam a observar como se dão as práticas laborais e/ou voltadas para educação no cárcere a partir do estudo de determinadas unidades prisionais (CARVALHO, 2009; KRAHN, 2014; LOBO, 2009; MOREIRA, 2007; PRADO, 2015; ROCHA, 2016).

A atuação de grupos criminosos nas prisões também foi um tema recorrente. Embora só apareça na agenda de pesquisa a partir de 2009, a temática foi abordada em treze $(9,4 \%)$ trabalhos. Dentro desse tema, destacam-se os trabalhos que tratam do Primeiro Comando da Capital - PCC (BIONDI, 2009; BIONDI, 2014; BRANDÁO, 2011; DIAS, 2011; FRESTON, 2010; GRIMBERG, 2009; LIMA, 2013; MOREIRA, 2012; RUOTTI, 2016; SILVA, 2014; SILVESTRE, 2016). Mais recentemente, notamos o surgimento de estudos de outros grupos localizados na regiāo Nordeste do país (SANTOS, C. E. B., 2015; SILVA, 2017). O discurso punitivo, entendido aqui como o elemento simbólico que compóe o campo normativo da punição e de sua crítica, foi tema de parte dos trabalhos encontrados, estando presente como componente central em pelo menos treze $(9,4 \%)$ deles. Esses trabalhos apresentam, de forma geral, discussões teóricas e críticas a partir do debate empreendido pela Criminologia, muitas vezes ratificando o debate sobre a pena privativa de liberdade (BARROS, 2012; MACEDO, 2017; SANTOS, J. W., 2016; TEIXEIRA, 2006; VIANNA, 2010). A prática e a conversão religiosa no cárcere aparecem como tema em onze $(7,9 \%)$ estudos. 
Dentre os estudos elencados, percebemos que o modelo da Associação de Proteção e Assistência aos Condenados - Apac apareceu como objeto em destaque (OLIVEIRA, 2013; PASTI, 2016; VARGAS, 2011). A atenção nas questôes de conversão via religião foi algo bem marcado em diversos desses trabalhos (ARAÚJO, 2009; DIAS, 2005; GUSMÃO, 2011; KRONBAUER, 2010; LOBO, 2002). Os processos referentes ao cotidiano, dinâmica e cultura prisional foram tema central de sete (5\%) trabalhos (DANTAS PEREIRA, 2004; FONSECA, 2002; GODOI, 2010; 2015; LIMA COSTA, 2002; LOBO, 2009; SILVA, 2000; SILVESTRE, 2011). Todos, de alguma forma, trabalham as diversas imbricaçôes presentes nas relaçóes sociais estabelecidas a partir do confinamento. $\mathrm{O}$ estudo do trabalho executado nas prisóes por agentes penitenciários parece ser uma nova tendência dentro dos estudos prisionais. Além da preocupação com os internos das prisóes, os estudos sobre agentes penitenciários, um total de cinco $(3,6 \%)$, nos ajudam a olhar a partir de outra perspectiva as questóes que envolvem o confinamento (MONTEIRO, 2013; REIS, 2012; SABAINI, 2012; SARMENTO, 2014; SIQUEIRA, 2016). No que se refere aos aspectos metodológicos mobilizados nas teses e nas dissertações examinadas, a maior parte dos trabalhos empregou técnicas de pesquisa qualitativas. Pelo menos oitenta $(57,6 \%)$ trabalhos mencionaram ferramentas desse tipo em seus resumos. Chama atenção, do mesmo modo, o grande número de resumos que não mencionam a estratégia metodológica empregada, um total de 35 (25,2\%) trabalhos. Dentre as técnicas de pesquisa, a entrevista foi a mais usada, em pelo menos 41 (29,5\%) trabalhos. A segunda técnica mais mencionada nos resumos foi a etnografia, em dezoito $(12,9 \%)$, seguida pela análise documental, em catorze $(10,1 \%)$, pela história de vida, em doze $(8,6 \%)$, e pela observaçáo (direta ou participante), em oito $(5,8 \%)$. Poucas pesquisas trabalharam com análises qualitativas aliadas a descriçóes quantitativas: um total de oito $(5,8 \%)$. Além disso, apenas um trabalho usou análises estatísticas mais robustas (BASEGIO, 2009).

\section{Quadro 1}

\section{Temas mais recorrentes na base de dados pesquisada}

\begin{tabular}{|c|c|c|}
\hline Tema $\left(^{*}\right)$ & Número de trabalhos & Referência - autor, data \\
\hline Mulheres nas prisóes & 25 & $\begin{array}{l}\text { Almeida, 2006; Andrade, 2011; Andrade, 2015; Bitencourt, } 2012 \text {; } \\
\text { Bumachar, 2016; Cardoso, 2017; Carvalhido, 2016; Costa, 2011; } \\
\text { Santos, 2016; França, 2013; L. A. Santos, 2015; Lago, 2014; } \\
\text { Lima, 2016; Lopes, 2014; Martins, 2016; Massaro, 2014; } \\
\text { Matsuda, 2016; Moura, 2005; Padovani, 2015; Pereira, 2008; } \\
\text { Quadrado, 2014; Quintino, 2005; Reif, 2016. }\end{array}$ \\
\hline $\begin{array}{l}\text { Ressocialização, } \\
\text { trabalho e educação } \\
\text { no cárcere }\end{array}$ & 15 & $\begin{array}{l}\text { Bastos, 2012; Carvalho, 2009; Costa, 2005; Duarte, 2013; } \\
\text { Krahn, 2014; Lobo, 2009; Madeira, 2004; Madeira, 2008; } \\
\text { Miranda, 2009; Moreira, 2007; Prado, 2015; Rocha, 2016; } \\
\text { Toledo, 2013; Vasconcelos, 2013. }\end{array}$ \\
\hline $\begin{array}{l}\text { Grupos criminosos } \\
\text { nas prisōes }\end{array}$ & 13 & $\begin{array}{l}\text { Biondi, 2009; Biondi, 2014; Brandão, 2011; C. } \\
\text { E. B. Santos, 2015; Dias, 2011; Freston, 2010; Grimberg, } \\
\text { 2009; Lima, 2013; Moreira, 2012; Ruotti, 2016; Silva, 2014; } \\
\text { Silva, 2017; Silvestre, } 2016 .\end{array}$ \\
\hline
\end{tabular}




\section{Quadro 1 - continuação}

\begin{tabular}{lcl}
\hline \multicolumn{1}{c}{ Tema $\left({ }^{*}\right)$} & Número de trabalhos & \multicolumn{1}{c}{ Referência - autor, data } \\
\hline $\begin{array}{l}\text { Discurso punitivo, } \\
\text { política penal e } \\
\text { prisional }\end{array}$ & 13 & $\begin{array}{l}\text { Almeida, 2005; Araújo, 2008; Barros, 2007; Barros, 2012; } \\
\text { César Segundo, 2011; Cypreste, 2010; J. W. Santos, 2016; } \\
\text { Macedo, 2017; Pinto, 2006; Teixeira, 2006; Vasconcellos, 2008; } \\
\text { Vianna, 2010. }\end{array}$ \\
\hline Religião nas prisões & 11 & $\begin{array}{l}\text { Andrade, 2014; Araújo, 2009; Bicca, 2005; Dias, 2005; } \\
\text { Gusmão, 2011; Kronbauer, 2010; Lobo, 2002; Nunes, 2017; } \\
\text { Oliveira, 2013; Pasti, 2016; Vargas, 2011. }\end{array}$ \\
\hline $\begin{array}{l}\text { Cotidiano, dinâmica } \\
\text { e cultura prisional }\end{array}$ & 7 & $\begin{array}{l}\text { Dantas Pereira, 2004; Fonseca, 2002; Godoi, 2010; 2015; } \\
\text { Lima Costa, 2002; Lobo, 2009; Silva, 2000; Silvestre, 2011. }\end{array}$ \\
\hline $\begin{array}{l}\text { Agentes } \\
\text { penitenciários }\end{array}$ & 5 & $\begin{array}{l}\text { Monteiro, 2013; Reis, 2012; Sabaini, 2012; Sarmento, 2014; } \\
\text { Siqueira, 2016. }\end{array}$ \\
\hline
\end{tabular}

$\left.{ }^{*}\right)$ Entende-se por tema, nesse contexto, os assuntos incontornáveis e centrais nos trabalhos pesquisados. Essa classificação foi elaborada por nós e pode náo necessariamente coincidir com o objeto de pesquisa ou problema de estudo dos trabalhos analisados.

Fonte: Elaboração própria.

\section{Considerações finais: retomando o balanço da literatura sobre prisões no país}

No balanço realizado em 2006, a partir do levantamento de teses e de dissertações em ciências sociais disponíveis no Banco de Teses da Capes, Fernando Salla apontava para os sete desafios da produção acadêmica nesse campo, a qual o autor igualmente constatava que havia se adensado muito, a partir dos anos 2000. Pode ser interessante, para este levantamento, retomar esses pontos para diagnosticar como está o desenvolvimento dessa área de investigação no Brasil, seus avanços e os pontos de estagnação, embora em relação a vários tópicos seja possível apenas especular acerca do estado presente da produçáo da área, já que um diagnóstico mais rigoroso dependeria de análise qualitativa aprofundada das teses e das dissertaçōes produzidas, o que ainda não foi possível no momento da elaboração deste texto.

Um primeiro desafio, para Salla, inclusive considerado por ele mais fundamental, consistiria no tratamento teórico dado ao tema no que diz respeito aos estudos realizados no
Brasil. Haveria, naquele momento, uma reprodução das teorias consideradas clássicas na área e seus desdobramentos - como os trabalhos de Erving Goffman e de Michel Foucault -, sem formulaçôes mais originais que contemplassem os desafios próprios ao contexto nacional. No momento, não foi possível identificar se houve a preocupação, em determinados trabalhos, de não apenas reproduzir teorias e teses da literatura internacional, que foi sem dúvida cada vez mais incorporada no Brasil em sua diversidade. Uma pista aqui encontrada são os inúmeros trabalhos de perspectiva indutiva, que muitas vezes valorizam mais os próprios achados que um diálogo mais profundo com a literatura da área. Outro indício sobre essa hipótese é o grande número de resumos examinados que nem mesmo mencionavam qual estratégia metodológica havia sido empregada na pesquisa: $35(25,2 \%)$ trabalhos. Provavelmente, essas evidências estejam associadas igualmente ao pouco rigor teórico, ao indicar que a área ainda tem muito a avançar nesse aspecto, tal como afirmava Salla.

Um segundo desafio consistiria em pensar a ação governamental na área prisional, articulada às demais políticas públicas. 
Haveria, novamente segundo Salla, um divórcio entre os estudos acadêmicos na área de políticas públicas, com pouco interesse com relação à área de segurança pública e, mais especificamente, das políticas para as prisóes:

não se produziu ainda para as políticas de segurança e em particular as direcionadas para as prisōes análise que se voltem para essas três dimensōes: os fatores que interferem na sua formulação; como são implementadas tais políticas pelos órgãos responsáveis e ainda quais os resultados ou o impacto dessas políticas. (SALLA, 2006, p. 115).

No período estudado neste levantamento, foi possível constatar um crescimento de investigaçôes voltadas para as políticas prisionais, inclusive dos discursos punitivos que muitas vezes fundamentam tais políticas, mas trata-se ainda de campo a ser igualmente mais bem explorado. Como visto, a ciência política foi uma das áreas com menor concentração de trabalhos sobre prisóes, indicando que esse setor das políticas públicas não tem sido tão incorporado no âmbito dessa disciplina, como acontece com outras áreas de atuaçáo do Estado.

De forma complementar ao ponto anterior, haveria, mais uma vez de acordo com Salla, uma segmentação da produção acadêmica sobre prisóes. Haveria a necessidade de entrecruzar os estudos nas esferas do Executivo, do Ministério Público e do Legislativo, para compreender os efeitos das açóes de cada poder sobre as prisóes. Também seria necessário aprofundar os efeitos das políticas na área prisional nas esferas dos poderes Federal, Estadual e Municipal. O autor chamava a atenção também para o impacto da implantação de unidades prisionais nos espaços municipais, por exemplo. Tal tema foi aprofundado em trabalhos como o de Silvestre (2011), Redígolo (2013) e Godoi (2015) e no período por nós estudado.

Um quarto desafio consistiria num caráter ainda provinciano dos estudos sobre prisões no país, com ausência quase total de estudos comparados com outros países, quer os latino-americanos, quer os de outras partes do mundo. Possibilitaria assim questionar se o Brasil estaria ou náo acompanhando as tendências de crescimento do encarceramento, como já havia sido identificado pela literatura internacional. Nesse aspecto, a grande maioria das investigaçóes permaneceu ainda circunscrita aos estudos nacionais.

Outro desafio consistira na ênfase dada nos trabalhos até então realizado no viés monográfico, com a investigação voltada para temas específicos, como educação, trabalho e saúde no interior do cárcere, ou ao estudo aprofundado de unidades específicas. Seriam, até então, raros os trabalhos que se aventurariam em investigar as tendências das políticas penitenciárias em períodos mais longos. No que diz respeito aos temas no período por nós estudado, foi possível constatar o crescimento de temas tais como mulheres nas prisóes, grupos no interior e fora das prisóes, religiáo, agentes penitenciários, entre outros, ampliando consideravelmente o espectro de temas na área.

Um sexto desafio, sempre de acordo com Salla, consistiria na presença de uma agenda ainda "tradicional" no campo, circunscrita, sobretudo a temas como trabalho, educaçáo e ressocialização, com poucos exemplos de estudos, até aquele momento, sobre as relaçóes de poder no interior das prisóes, entre administração e presos, sobre a construção de grupos e identidades no interior das prisóes, sobre as chamadas "gangues" prisionais, sobre os movimentos de revolta e rebelióes, bem como acerca das ligaçóes da instituição com o mundo exterior. Percebe-se neste novo levantamento que os estudos considerados "tradicionais" por Salla contemplaram apenas $8,6 \%$ das pesquisas, sendo que surgiram diversos trabalhos sobre as dinâmicas diversas de poder dentro e fora das prisóes. Assim, como já afirmado, na produção mais recente, 
as investigaçóes avançaram muito, transbordando a agenda considerada tradicional, antes identificada por Salla.

Um último desafio se deveria à precariedade de fontes de informaçáo de boa qualidade na área de segurança pública e das prisóes no Brasil, sendo gerados dados estatísticos de qualidade insatisfatória e sem regularidade. Essa é provavelmente a frente em que menos avançamos, e a total predominância de estudos qualitativos no período por nós estudado corrobora a constatação de que a agenda de pesquisa permanecerá estagnada nesse âmbito de investigação, ao depender dos dados estatais para análise.
Como afirmado no início de nosso texto, o objetivo perseguido aqui consistiu, sobretudo, em mapear, em linhas gerais, as dissertaçóes e teses produzidas sobre a temática prisional no período adotado. A permanente revisão dos estudos das ciências sociais na área, entre outros benefícios, pode ajudar aos novos pesquisadores a se situarem num campo dinâmico e em expansão, que acompanha criticamente o crescimento do encarceramento no país e seus efeitos nas dinâmicas políticas e sociais, ao desempenhar desse modo não apenas um papel acadêmico, mas também político e não menos relevante, num país ainda caracterizado pela presença da violência e da desigualdade em dimensôes alarmantes.

\section{Referências}

ADORNO, S. A criminalidade urbana violenta no Brasil: um recorte temático. Revista Brasileira de Informação Bibliográfica em Ciências Sociais, Rio de Janeiro, n. 35, p. 3-24, 1993.

ALMEIDA, F. M. Heranças perigosas: arqueogenealogia da "periculosidade" na legislaçấo penal brasileira. 2005. $208 \mathrm{f}$. Dissertação (Mestrado em Sociologia) - Universidade Federal do Rio Grande do Sul, Porto Alegre, 2005.

ALMEIDA, M. L. O. Vozes de dentro... de mulheres... e de muralhas: um estudo sobre jovens presidiárias em Salvador, Bahia. 2006. 206 f. Dissertação (Mestrado em Ciências Sociais) - Universidade Federal da Bahia, Salvador, 2006.

ALVAREZ, M. C. Bacharéis, criminologistas e juristas: saber jurídico e nova escola penal no Brasil. São Paulo: IBCCRIM, 2003.

ANDRADE, B. S. A. Batista de. Entre as leis da Ciência, do Estado e de Deus: o surgimento dos presídios femininos no Brasil. 2011. 316 f. Dissertaçâo (Mestrado em Antropologia Social) - Faculdade de Filosofia, Letras e Ciências Humanas, Universidade de São Paulo, São Paulo, 2011.

ANDRADE, E. L. A rua dos irmãos: uma etnografia na prisão. 2014. 130 f. Dissertação (Mestrado em Sociologia) Universidade Federal do Ceará, Fortaleza, 2014.

ANDRADE, F. S. Pela cortina do desvio: a trajetória de mulheres presas do presídio feminino de Nossa Senhora do Socorro, SE. 2015. 172 f. Dissertação (Mestrado em Antropologia) - Universidade Federal de Sergipe, São Cristóvão, 2015.

ARAÚJO, A. A. Sistema penal brasileiro, MST e a reprodução da dominação de classes no campo. 2008. 134 f. Dissertaçâo (Mestrado em Ciências Sociais) - Universidade Estadual de Londrina, Londrina, 2008. 
ARAÚJO, F. F. Mercado de almas aflitas: crime, castigo e conversão religiosa. 2009. 105 p. Dissertação (Mestrado em Sociologia) - Universidade Federal da Paraíba, João Pessoa, 2009.

BARROS, R. A. L. Os dilemas da sociedade punitiva: reflexōes sobre os debates em torno da sociologia da punição. 2007. 182 f. Dissertação (Mestrado em Ciências Sociais) - Faculdade de Filosofia e Ciências, Universidade Estadual Paulista, Marília, 2007.

A reinvenção da prisão: a expansão prisional no Estado de São Paulo e as consequências do encarceramento massivo (1985-2010). 2012. 220 f. Tese (Doutorado em Ciências Sociais) - Faculdade de Filosofia e Ciências, Universidade Estadual Paulista, Marília, 2012.

BASEGIO, L. J. A transição criminológica na RMPA entre 1991 e 2000: a sua manifestaçẫo através da análise dos apenados e dos delitos entre os municípios da região metropolitana de Porto Alegre (RMPA). 2009. 105 f. Dissertação (Mestrado em Sociologia) - Universidade Federal do Rio Grande do Sul, Porto Alegre, 2009.

BASTOS, A. A. Escola e vida no cárcere: uma etnografia no Presídio Regional de Santa Maria. 2012. 73 p. Dissertação (Mestrado em Ciências Sociais) - Universidade Federal de Santa Maria, Santa Maria, 2012.

BICCA, A. Os eleitos do cárcere: etnografia sobre violência e religião no sistema prisional gaúcho. 2005. 198 f. Dissertação (Mestrado em Antropologia) - Universidade Federal do Rio Grande do Sul, Porto Alegre, 2005.

BIONDI, K. Junto e misturado: imanência e transcendência no PCC. 2009. 198 f. Dissertaçáo (Mestrado em Antropologia Social) - Universidade Federal de São Carlos, São Carlos, 2009.

Etnografia no movimento: território, hierarquia e lei no PCC. 2014. 334 f. Tese (Doutorado em Antropologia Social) - Universidade Federal de São Carlos, São Carlos, 2014.

BITENCOURT, A. H. Mulheres \& sistema prisional: o sentido do trabalho para quem viveu e vive sob a égide do cárcere. 2012. 115 f. Dissertação (Mestrado em Ciências Sociais) - Pontifícia Universidade Católica do Rio Grande do Sul, Porto Alegre, 2012.

BRANDÃO, T. S. Atrás das grades: redes sociais, habitus e interaçâa social no sistema carcerário do RN. 2011. $184 \mathrm{f}$. Tese (Doutorado em Ciências Sociais) - Universidade Federal do Rio Grande do Norte, Natal, 2011.

BUMACHAR, B. L. Nem dentro, nem fora: a experiência prisional de estrangeiras em São Paulo. 2016. 380 f. Tese (Doutorado em Antropologia Social) - Instituto de Filosofia e Ciências Humanas, Universidade Estadual de Campinas, Campinas, 2016.

CAMPOS, M.; ALVAREZ, M. C. Políticas de segurança, violência e punição no Brasil (2000-2016). In: MICELI, S.; MARTINS, C. (Orgs.). Sociologia brasileira hoje. São Paulo: Ateliê Editorial, 2017. p. 143-213.

CARDOSO, C. M. Histórias das mulheres privadas de liberdade em Manaus: vidas marcadas pela pobreza, violência e abandono. 2017. 186 f. Dissertação (Mestrado em Sociologia) - Universidade Federal do Amazonas, Manaus, 2017. 
CARVALHIDO, M. L. L. Histórias de vida, prisão e estigma: o uso da tornozeleira eletrônica por mulheres no estado do Rio de Janeiro. 2016. 148 f. Dissertação (Mestrado em Sociologia Política) - Universidade Estadual do Norte Fluminense Darcy Ribeiro, Campos dos Goytacazes, 2016.

CARVALHO, R. A. M. O tempo como pena e o trabalho como "prêmio": o cotidiano dos presos da Penitenciária Industrial Regional de Sobral (PIRS). 2009. 190 f. Dissertação (Mestrado em Sociologia) - Universidade Federal do Ceará, Fortaleza, 2009.

CÉSAR SEGUNDO, B. W. Os sentidos do aprisionamento na contemporaneidade: um estudo de caso no Presídio do Serrotão em Campina Grande, PB. 2011. 216 f. Tese (Doutorado em Sociologia) - Universidade Federal da Paraíba, João Pessoa, 2011.

CLEMMER, D. The prison community. 2. ed. New York: Holt, Rinehart and Winston, 1958.

COSTA, E. C. P. Enfim, a liberdade: as mulheres e a vivência pós-cárcere. 2011. 262 f. Tese (Doutorado em Sociologia) - Universidade Federal de Pernambuco, Recife, 2011.

COSTA, J. B. Militância, dádiva e conversão religiosa: o caso dos presidiários evangélicos em busca da dupla salvaçấo. 2005. 134 f. Dissertação (Mestrado em Sociologia) - Universidade Federal de Pernambuco, Recife, 2005.

CYPRESTE, A. D. Crime e trabalho no Brasil: o controle das drogas entre a Primeira República e o Código Penal de 1940. 2010. 153 f. Dissertação (Mestrado em Sociologia Política) - Universidade Estadual do Norte Fluminense Darcy Ribeiro, Campos dos Goytacazes, 2010.

DANTAS PEREIRA, E. O pacto velado: estudo etnográfico sobre a sociabilidade entre apenados de regime fechado na Penitenciária Agrícola de Mossoró/RN. 2004. 103 f. Dissertação (Mestrado em Antropologia) - Universidade Federal de Pernambuco, Recife, 2004.

DIAS, C. C. N. A igreja como refúgio e a biblia como esconderijo? Conversão religiosa, ambiguidade e tensão entre presos evangélicos e massa carcerária. 2005. 204 f. Dissertação (Mestrado em Sociologia) - Universidade de São Paulo, São Paulo, 2005.

Da pulverização ao monopólio da violência: expansăo e consolidação do Primeiro Comando da Capital (PCC) no sistema carcerário paulista. 2011. 386 f. Tese (Doutorado em Sociologia) - Faculdade de Filosofia, Letras e Ciências Humanas, Universidade de São Paulo, São Paulo, 2011.

DUARTE, R. L. Choque cultural e aplicação penal: uma análise sobre o indivíduo e a ressocialização na sociedade atual. 2013. 93 f. Dissertação (Mestrado em Ciências Sociais) - Universidade do Vale do Rio dos Sinos, São Leopoldo, 2013.

FONSECA, M. Cartografia das resistências: uma análise antropológica do pavilhão oito da casa de detenção de São Paulo. 2002. 162 f. Dissertação (Mestrado em Ciências Sociais) - Pontifícia Universidade Católica de São Paulo, São Paulo, 2002.

FOUCAULT, M. Vigiar e punir: história da violência nas prisōes. Petrópolis: Vozes, 1977. 
FRANÇA, M. H. O. Prisão, tráfico e maternidade: um estudo sobre mulheres encarceradas. 2013. 237 f. Tese (Doutorado em Sociologia) - Universidade Federal da Paraíba, João Pessoa, 2013.

FRESTON, R. B. Combate ao crime organizado: um estudo do PCC e das instituiçóes do sistema de justiça criminal. 2010. 92 f. Dissertação (Mestrado em Ciência Política) - Universidade Federal de São Carlos, São Carlos, 2010.

GARLAND, D. A cultura do controle: crime e ordem social na sociedade contemporânea. Rio de Janeiro: Revan, 2008.

GODOI, R. Ao redor e através da prisão: cartografias do dispositivo carcerário contemporâneo. 2010. 202 f. Dissertação (Mestrado em Sociologia) - Universidade de São Paulo, São Paulo, 2010.

. Fluxos em cadeia: as prisôes em São Paulo na virada dos tempos. 2015. 246 f. Tese (Doutorado em Sociologia) - Faculdade de Filosofia, Letras e Ciências Humanas, Universidade de São Paulo, São Paulo, 2015.

GOFFMAN, E. Asylums: essays on the social situation of mental patients and other inmates. New York: Anchor Books, 1961.

GRIMBERG, S. V. Luta de guerreiros castigos de ninjas e amor de rainhas: etnografia de uma rebeliāo prisional. 2009. 141 f. Dissertação (Mestrado em Antropologia Social) - Universidade Federal de São Carlos, São Carlos, 2009.

GUSMÃO, E. H. A. Dinâmicas prisionais e religiāo: uma análise sobre as trajetórias e experiências de detentos em processos de conversão. 2011. 176 f. Tese (Doutorado em Antropologia) - Universidade Federal de Pernambuco, Recife, 2011.

KRAHN, N. M. W. Ressocializando? As percepções sobre a implementação de políticas laborativas e educacionais em uma unidade prisional. 2014. 250 f. Dissertação (Mestrado em Ciências Sociais) - Universidade Federal da Bahia, Salvador, 2014.

KRONBAUER, J. L. O crente e o cárcere: estudo sociológico sobre evangélicos em prisões gaúchas. 2010. 111 f. Dissertação (Mestrado em Ciências Sociais) - Pontifícia Universidade Católica do Rio Grande do Sul, Porto Alegre, 2010.

LAGO, N. B. Mulheres na prisão: entre famílias, batalhas e a vida normal. 2014. 95 f. Dissertação (Mestrado em Antropologia) - Faculdade de Filosofia, Letras e Ciências Humanas, Universidade de São Paulo, São Paulo, 2014.

LEMOS BRITO, J. G. Os systemas penitenciários do Brasil. Rio de Janeiro: Imprensa Nacional, 1924.v 1.

. As mulheres criminosas e seu tratamento penitenciário. Arquivos Penitenciários do Brasil, Rio de Janeiro, v. 3, n. 3-4, p. 61-78, 1942.

LIMA, C. P. S. As mulheres nas redes do tráfico de drogas em Alagoas. 2016. 143 f. Dissertação (Mestrado em Sociologia) - Instituto de Ciências Sociais, Universidade Federal de Alagoas, Maceió, 2016.

LIMA, J. S. F. Mulher fiel: as famílias das mulheres dos presos relacionados ao Primeiro Comando da Capital. 2013. 164 f. Dissertação (Mestrado em Antropologia Social) - Universidade Federal de São Carlos, São Carlos, 2013. 
LIMA COSTA, L. A. Do corpo do infrator à figura do delinquente: uma trajetória institucional. 2002. 234 f. Dissertação (Mestrado em Ciências Sociais) - Universidade Federal da Bahia, Salvador, 2002.

LOBO, E. S. "Igrejas atrás das grades": um estudo sobre a atuação de católicos e evangélicos no sistema penitenciário do Rio de Janeiro. 2002. 115 f. Dissertaçấo (Mestrado em Sociologia) - Universidade Federal do Rio de Janeiro, Rio de Janeiro, 2002.

A escola por trás dos muros da prisão: percepçóes de alunos detentos sobre educação, religiáo e vida cotidiana. 2009. 199 f. Tese (Doutorado em Ciências Sociais) - Universidade Federal do Rio de Janeiro, Rio de Janeiro, 2009.

LOPES, K. M. Prisão e maternidade: a experiência de presas e egressas do sistema prisional. 2014. 149 f. Dissertação (Mestrado em Ciências Sociais) - Universidade Federal de São Paulo, São Paulo, 2014.

LOURENÇO, L. C. Contribuições pioneiras das ciências sociais no estudo sobre as prisôes brasileiras do séc. XX. Vivência, Natal, v. 1, n. 46, p. 169-180, 2016.

MACEDO, A. A. Direito, discurso, dogma: uma crítica à mentalidade positivista e punitivista do Direito Penal Brasileiro. 2017. 95 f. Dissertação (Mestrado em Ciências Sociais) - Universidade Federal do Espírito Santo, Vitória, 2017.

MADEIRA, L. M. A atuação da sociedade civil na ressocialização de egressos do sistema penitenciário: estudo de caso sobre a Faesp. 2004. 244 f. Dissertação (Mestrado em Sociologia) - Instituto de Filosofia e Ciências Humanas, Universidade Federal do Rio Grande do Sul, Porto Alegre, 2004.

Trajetórias de homens infames: políticas públicas penais e programas de apoio a egressos do sistema penitenciário no Brasil. 2008. 358 f. Tese (Doutorado em Sociologia) - Instituto de Filosofia e Ciências Humanas, Universidade Federal do Rio Grande do Sul, Porto Alegre, 2008.

MARTINS, M. A. S. Filhos concebidos no cárcere: mães apenadas do Complexo Penitenciário Anísio Jobim, Compaj. 2016. 193 p. Tese (Doutorado em Sociedade e Cultura na Amazônia) - Universidade Federal do Amazonas, Manaus, 2016.

MASSARO, C. M. Trabalho em tempos de crise: a superexploraçâo do trabalho penal nos Centros de Ressocializaçáo Femininos do Estado de Sáo Paulo. 2014. 368 f. Tese (Doutorado em Ciências Sociais) - Faculdade de Ciências e Letras, Universidade Estadual Paulista Júlio de Mesquita Filho, Araraquara, 2014.

MATSUDA, F. E. Sob fogo cruzado: a gestão de mulheres e a justiça criminal paulista. 2016. 200 f. Tese (Doutorado em Sociologia) - Faculdade de Filosofia, Letras e Ciências Humanas, Universidade de São Paulo, São Paulo, 2016.

MENEZES, W. F. O esgotamento da maquinaria carcerária: uma análise do sistema penitenciário do estado de São Paulo (2000-2010). 2013. 130 f. Dissertação (Mestrado em Ciências Sociais) - Faculdade de Filosofia e Ciências, Universidade Estadual Paulista Júlio de Mesquita Filho, Marília, 2013.

MIRANDA, M. M. A reabilitação do criminoso no discurso norte-americano: uma proposta alternativa ao cárcere duro. 2009. 121 f. Dissertação (Mestrado em Ciências Sociais) - Universidade Federal de Juiz de Fora, Juiz de Fora, 2009. 
MISSE, M.; LIMA, R. K.; MIRANDA, A. P. M. Violência, criminalidade, segurança pública e justiça criminal no Brasil: uma bibliografia. Revista Brasileira de Informação Bibliográfica em Ciências Sociais, Rio de Janeiro, n. 50, p. 45-123, 2000.

MONTEIRO, L. A permeabilidade das grades na busca cotidiana pela ordem: um estudo sobre agentes penitenciários em Salvador, BA. 2013. 213 f. Dissertação (Mestrado em Ciências Sociais) - Universidade Federal da Bahia, Salvador, 2013.

MOREIRA, A. O PCC em São Paulo: "coletivo de presos" ou "organização criminosa”? 2012. 96 f. Dissertaçáo (Mestrado em Ciência Política) - Universidade Federal de São Carlos, São Carlos, 2012.

MOREIRA, H. L. F. Trabalho, códigos, gratidão e reciprocidade na prisão: um estudo de caso na Penitenciária Estadual de Parnamirim, no estado do Rio Grande do Norte. 2007. 347 f. Tese (Doutorado em Ciências Sociais) - Universidade Federal do Pará, Belém, 2007.

MOURA, M. J. Porta fechada, vida dilacerada: mulher, tráfico de drogas e prisão: estudo realizado no presídio feminino do Ceará, Fortaleza. 2005. 145 f. Dissertaçấo (Mestrado em Políticas Públicas) - Universidade Estadual do Ceará, Fortaleza, 2005.

NUNES, A. I. C. Discurso religioso no cárcere: caminhos e possibilidades. 2017. 157 f. Dissertação (Mestrado em Ciências Sociais) - Universidade Federal de Juiz de Fora, Juiz de Fora, 2017.

OLIVEIRA, V. N. Prisóes sem guardas: uma experiência liderada por grupos religiosos. 2013. 116 f. Dissertação (Mestrado em Sociologia) - Universidade Federal de Minas Gerais, Belo Horizonte, 2013.

PADOVANI, N. C. "Perpétuas espirais": falas do poder e do prazer sexual em trinta anos (1977-2009) na história da Penitenciária Feminina da Capital. 2010. 186 f. Dissertação (Mestrado em Sociologia) - Universidade Estadual de Campinas, Campinas, 2010.

Sobre casos e casamentos: afetos e "amores" através de penitenciárias femininas em São Paulo e Barcelona. 2015. 368 f. Tese (Doutorado em Antropologia Social) - Universidade Estadual de Campinas, Campinas, 2015.

PASTI, N. M. L. Representações de gênero na aplicação do método Apac (Associação de Proteção e Assistência aos Condenados) em Itaúna, Minas Gerais. 2016. 109 f. Dissertação (Mestrado em Sociologia Política) - Universidade Estadual do Norte Fluminense Darcy Ribeiro, Campos dos Goytacazes, 2016.

PEREIRA, S. V. J. Trajetórias de vida de mulheres presidiárias envolvidas com o tráfico de drogas em Belo Horizonte. 2008. 124 f. Dissertação (Mestrado em Ciências Sociais) - Universidade Federal de Minas Gerais, Belo Horizonte, 2008.

PINTO, N. M. Penas e alternativas: um estudo sociológico dos processos de agravamento das penas e de despenalização no sistema de criminalização brasileiro (1984-2004). 2006. 271 f. Tese (Doutorado em Sociologia e Antropologia) - Instituto de Filosofia e Ciências Sociais. Universidade Federal do Rio de Janeiro, Rio de Janeiro, 2006.

PRADO, A. S. Educação nas prisões: desafios e possibilidades do ensino praticado nas Unidades Prisionais de Manaus. 2015. 106 f. Dissertação (Mestrado em Sociologia) - Universidade Federal do Amazonas, Manaus, 2015. 
QUADRADO, J. C. Fragmentos de uma genealogia de mulheres no contexto prisional: um estudo de relatos sobre a experiência de aprisionamento. 2014. 208 f. Tese (Doutorado em Sociologia) - Universidade de Brasília, Brasília, DF, 2014.

QUINTINO, S. Creche na prisão feminina do Paraná: humanização da pena ou intensificação do controle social do Estado? 2005. 170 f. Dissertação (Mestrado em Sociologia) - Universidade Federal do Paraná, Curitiba, 2005.

REDÍGOLO, N. C. N. Para além dos muros e das grades: atitudes e valores em relação às instituiçôes carcerárias do município de Valparaíso/SP. 2013. 123 f. Dissertaçăo (Mestrado em Ciências Sociais) - Universidade Estadual Paulista Júlio de Mesquita Filho, Marília, 2013.

REIF, K. S. Em liberdade: narrativas biográficas de mulheres com experiências de encarceramento. 2016. 88 f. Dissertação (Mestrado em Ciências Sociais) - Pontifícia Universidade Católica do Rio Grande do Sul, Porto Alegre, 2016.

REIS, M. P. Entre o poder e a dor: representaçōes sociais da corrupção e da violência no sistema penitenciário de São Paulo. 2012. 376 f. Tese (Doutorado em Sociologia) - Universidade de Brasília, Brasília, 2012.

ROCHA, F. V. A escola por trás das grades: educaçấo escolar no sistema prisional do Estado do Paraná, 1990-2016. 2016. 108 f. Dissertação (Mestrado em Ciências Sociais) - Universidade Estadual de Maringá, Maringá, 2016.

ROTHMAN, D. The discovery of asylum: social order and disorder in the Republic. New York: Little, Brown and Company, 1990.

RUOTTI, C. Pretensão de legitimidade do PCC: justificação e reconhecimento de suas práticas nas periferias da cidade de São Paulo. 2016. 226 f. Doutorado (Mestrado em Sociologia) - Universidade de São Paulo, São Paulo, 2016.

RUSCHE, G.; KIRCHHEIMER, O. Puniçāo e estrutura social. 2. ed. Rio de Janeiro: Revan, 2004.

SABAINI, R. T. Uma cidade entre presídios: ser agente penitenciário em Itirapina-SP. 2012. Dissertação (Mestrado em Antropologia Social) - Faculdade de Filosofia, Letras e Ciências Humanas, Universidade de São Paulo, São Paulo, 2012.

SALLA, F. A pesquisa sobre as prisōes: um balanço preliminar. In: KOERNER, A. (Org.). História da justiça penal no Brasil: pesquisas e análises. São Paulo: Instituto Brasileiro de Ciências Criminais, 2006. p. 107-127.

. Vigiar e punir e os estudos prisionais no Brasil. Dilemas, Rio de Janeiro, ed. especial, n. 2, p. 29-43, 2017.

SANTOS, C. A. S. Ó pa í, prezada! Racismo e sexismo institucionais tomando bonde no Conjunto Penal Feminino de Salvador. 2014. 200 f. Dissertação (Mestrado em Estudos Interdisciplinares sobre Mulheres, Gênero e Feminismo) - Universidade Federal da Bahia, Salvador, 2012.

SANTOS, C. E. B. "Okaida" e "Estados Unidos", organizaçôes criminosas: a nova face da criminalidade na cidade de João Pessoa, Paraíba. 2015. 160 f. Dissertação (Mestrado em Ciências Sociais) - Universidade Federal do Rio Grande do Norte, Natal, 2015. 
SANTOS, F. C. M. Prisão e resistências: micropolítica da vida cotidiana em uma penitenciária para mulheres. 2016. 211 f. Tese (Doutorado em Sociologia) - Universidade Federal do Rio de Janeiro, Rio de Janeiro, 2016.

SANTOS, J. W. O estado do punir no Brasil: uma análise do processo legislativo em execução penal pós-abertura política entre ambiguidades histórico-discursivas. 2016. 129 f. Dissertação (Mestrado em Ciências Sociais) - Pontifícia Universidade Católica do Rio Grande do Sul, Porto Alegre, 2016.

SANTOS, L. A. Emoção e penalidade: mulheres no Complexo Penal Dr. João Chaves. 2015. 136 f. Dissertação (Mestrado em Antropologia Social) - Universidade Federal do Rio Grande do Norte, Natal, 2015.

SARMENTO, V. A. Análise do curso preparatório para agentes de segurança penitenciária femininas e sua relação com a formaçâa em direitos humanos. 2014. 209 f. Dissertaçấo (Mestrado em Direitos Humanos) - Universidade Federal da Paraíba, João Pessoa, 2014.

SILVA, D. E. M. Da festa à chacina: formas de gestão da violência e do crime em São Carlos/SP. 2014. 164 f. Dissertação (Mestrado em Sociologia) - Universidade Federal de São Carlos, São Carlos, 2014.

SILVA, T. Comando entre cadeias: do estado, dos frentes e das famílias. 2017. 127 f. Dissertaçâo (Mestrado em Ciências Sociais) - Universidade Federal do Recôncavo Baiano, Cachoeira, 2017.

SILVA, V. F. Compondo vidas, tecendo destinos: conflitos, territorialidades e trajetórias individuais na Penitenciária do Serrotão em Campina Grande, PB. 2000.115 f. Dissertação (Mestrado em Sociologia) - Universidade Federal de Campina Grande, Campina Grande, 2000.

SILVESTRE, G. Dias de visita: uma sociologia da puniçẫo e das prisōes em Itirapina. 2011. 192 f. Dissertação (Mestrado em Sociologia) - Universidade Federal de São Carlos, São Carlos, 2011.

"Enxugando Iceberg": como as instituiçôes estatais exercem o controle do crime em São Paulo. 2016. 314 f. Tese (Doutorado em Sociologia) - Universidade Federal de São Carlos, São Carlos, 2016.

SIQUEIRA, I. B. L. "Aqui ninguém fala, escuta ou vê”: relatos sobre o cotidiano profissional dos agentes de segurança penitenciária em Manaus. 2016. 224 f. Dissertaçấo (Mestrado em Sociologia) - Universidade do Amazonas, Manaus, 2016

SYKES, G. The society of captives: a study of a maximum-security prison. New Jersey: Princeton University, 1974.

TEIXEIRA, A. Do sujeito de direito ao estado de excȩaão: o percurso contemporâneo do sistema penitenciário brasileiro. 2006. 174 f. Dissertação (Mestrado em Sociologia) - Universidade de São Paulo, São Paulo, 2007.

TEIXEIRA, A.; OLIVEIRA, H. Maternidade e encarceramento feminino: o estado da arte das pesquisas no Brasil. Revista Brasileira de Informação Bibliográfica em Ciências Sociais, São Paulo, n. 81, p. 25-41, 2016.

TOLEDO, R. R. Os usos, significados e práticas da ressocialização do egresso do sistema prisional. 2013. 180 f. Dissertação (Mestrado em Ciências Sociais) - Universidade Federal de Juiz de Fora, Juiz de Fora, 2013. 
VARGAS, L. J. O. É possível humanizar a vida atrás das grades? Uma etnografia do método de gestão carcerária Apac. 2011. 252 f. Tese (Doutorado em Antropologia Social) - Universidade de Brasília, Brasília, DF, 2011.

VASCONCELLOS, F. B. A prisāo preventiva como mecanismo de controle e legitimação do campo jurídico. 2008. $178 \mathrm{f}$. Dissertaçáo (Mestrado em Ciências Sociais) - Pontifícia Universidade Católica do Rio Grande do Sul, Porto Alegre, 2008.

VASCONCELOS, F. E. A. Da prisão à "ressocialização": masculinidades aprisionadas na execução da Lei Maria da Penha. 2013. 155 f. Dissertaçăo (Mestrado em Sociologia) - Universidade Federal do Ceará, Fortaleza, 2013.

VIANNA, G. S. S. Disciplina, direito e subjetivaçẫo: uma análise de punição e estrutura social, vigiar e punir e cárcere e fábrica. 2010. 180 f. Dissertação (Mestrado em Sociologia) - Instituto de Filosofia e Ciências Humanas, Universidade Estadual de Campinas, Campinas, 2010.

ZALUAR, A. Um debate disperso: violência e crime no Brasil da redemocratização. São Paulo em Perspectiva, São Paulo, v. 13 , n. 3, p. 3-17, 1999 .

\section{Resumo}

Estudos sobre prisão: um balanço do estado da arte nas ciências sociais nos últimos vinte anos no Brasil (1997-2017)

A temática prisional, além de ganhar destaque na agenda de notícias e nas preocupaçōes sociais de nosso país, também se tornou mais expressiva na produção das ciências sociais no Brasil ao se constituir como um campo em expansão, ao longo dos últimos vinte anos. O objetivo deste texto é em mapear as dissertaçóes e teses produzidas nos programas de pós-graduação em ciências sociais, sociologia, ciência política e antropologia que tratem de questóes relativas aos estudos prisionais no período entre 1997 e 2017. Para alcançar tal propósito, foram consultados os repositórios acadêmicos de 56 instituições, além de sites de programas de pós-graduação nas áreas mencionadas. Ao todo, foram encontrados 139 trabalhos, entre dissertaçóes e teses, o que mostra a importância das prisóes na agenda de pesquisa das ciências sociais. Fica patente que a maioria dos trabalhos tem caráter empírico e foi realizada através de pesquisas em unidades prisionais ou com atores pertencentes a esse universo.

Palavras-chave: Prisão; Estudos Prisionais; Teses; Dissertaçôes; Sociologia da Punição.

\section{Abstract}

Prison studies in Brazil: a review of the current state of the art in Social Sciences in the last 20 years (1997-2017)

The prison theme, which has been highlighted in the news agenda and in the social concerns of our country, has become more expressive in social sciences studies in Brazil, as it has become a field in expansion over the last 20 years. The purpose of this paper is to map the theses and dissertations produced in postgraduate programs in social sciences, sociology, political science and anthropology that deal with questions related to prison studies in the period between 1997 and 2017. To achieve this purpose, academic repositories of 56 institutions as well as postgraduate program websites in the aforementioned areas were consulted. In all, 139 texts were found, among dissertations and theses, which shows the importance of prisons in the research agenda of the social sciences in Brazil. It becomes clear that most of the studies are empirical and were performed through research in prison units or with actors belonging to this universe.

Keywords: Prison; Prison studies; PhD Thesis; Masters Dissertations; Sociology of Punishment. 


\section{Résumé}

Études sur prison : une évaluation de l'état des sciences sociales au cours des vingt dernières années au Brésil (1997-2017)

Le thème des prisons, en plus de prendre de l'importance dans l'actualité et dans les préoccupations sociales de notre pays, est devenu plus expressif dans la production des sciences sociales au Brésil en étant un champ d'expansion, au cours des vingt dernières années. L'objectif de ce texte est de localiser et schématiser les dissertations et thèses produites dans les programmes postuniversitaires en sciences sociales, sociologie, sciences politiques et anthropologie qui traitent des questions liées aux études pénitentiaires entre 1997 et 2017. Pour atteindre cet objectif, on consulte les dépôts académiques de 56 institutions, ainsi que des sites de programmes de troisième cycle dans les domaines mentionnés. En tout, 139 articles ont été trouvés, entre dissertations et thèses, ce qui montre l'importance des prisons dans le programme de recherche des sciences sociales. Il est évident que la plupart des travaux sont empirique et ont été fait par la recherche dans les unités de prison ou avec des acteurs appartenant à cet univers.

Mots-clés: Prison; Études Pénitentiaires; Thèse de Doctorat; Mémoire de Maîtrise; Sociologie de la Punition. 


\section{Apêndice A - Lista de repositórios institucionais pesquisados}

\begin{tabular}{|c|c|c|}
\hline Programas & Repositório & Endereço eletrônico \\
\hline USP & tem & <http://www.teses.usp.br> \\
\hline UNICAMP & tem & <http://www.repositorio.unicamp.br> \\
\hline UNESP & tem & $<$ https://repositorio.unesp.br> \\
\hline UFSCAR & tem & <https://repositorio.ufscar.br> \\
\hline UFSC & tem & $<$ https://repositorio.ufsc.br> \\
\hline UFRR & tem & <http://www.bdtd.ufrr.br> \\
\hline UFRN & tem & <https://repositorio.ufrn.br> \\
\hline UFRJ & tem & <https://ppgsa.ifcs.ufrj.br> \\
\hline UFRGS & tem & <http://www.lume.ufrgs.br> \\
\hline UFPR & tem & $<$ <ttp://acervodigital.ufpr.br> \\
\hline UFPEL & fora do ar & <http://www2.ufpel.edu.br/tede> \\
\hline UFPE & tem & <http://www.repositorio.ufpe.br> \\
\hline UFPB & tem & $<$ http://bdtd.biblioteca.ufpb.br> \\
\hline UFPA & tem & $<$ http://repositorio.ufpa.br> \\
\hline UFMT & tem & <http://www.ufmt.br/ufmt/un/publicacao/ppge> \\
\hline UFMS & tem & $<$ http://posgraduacao.ufms.br/portal/trabalhos> \\
\hline UFMG & tem & <http://www.bibliotecadigital.ufmg.br> \\
\hline UFGD & tem & <https://tede.ufgd.edu.br> \\
\hline UFG & fora do ar & <http://repositorio.bc.ufg.br> \\
\hline UFF & tem & http://ppgantropologia.sites.uff.br> \\
\hline UFC & tem & $<$ http://www.repositorio.ufc.br> \\
\hline UFBA & tem & <http://www.repositorio.ufba.br> \\
\hline UFAM & tem & $<$ http://tede.ufam.edu.br> \\
\hline UFAL & tem & <http://www.repositorio.ufal.br> \\
\hline PUC-SP & tem & <https://sapientia.pucsp.br> \\
\hline PUC-RS & tem & <http://tede2.pucrs.br> \\
\hline PUC-MG & tem & <http://www.sistemas.pucminas.br/BDP> \\
\hline UFS & tem & $<$ https://ri.ufs.br> \\
\hline UFPI & tem & <http://repositorio.ufpi.br> \\
\hline UVV & não tem & \\
\hline UNISINOS & tem & <http://www.repositorio.jesuita.org.br> \\
\hline UNIOESTE & desatualizado & $\begin{array}{l}<\text { http://projetos.unioeste.br/pos/index.php?option=com_content\&task=view\&id= } \\
\text { 3001\&Itemid=833> }\end{array}$ \\
\hline UNIFESP & tem & <http://www2.unifesp.br/ciencias_sociais/defesas/dissertacoes-de-mestrado-defendidas $>$ \\
\hline UNB & tem & $<$ http://repositorio.unb.br> \\
\hline
\end{tabular}




\section{Apêndice A - continuação}

\begin{tabular}{|c|c|c|}
\hline Programas & Repositório & Endereço eletrônico \\
\hline UFU & tem & $<$ https://repositorio.ufu.br> \\
\hline UFSM & tem & $<$ http://repositorio.ufsm.br> \\
\hline UFRRJ CS & tem & <http://cursos.ufrri.br/posgraduacao/ppgcs/dissertacoes-defendidas> \\
\hline UFRRJ CPDA & fora do ar & $<$ http://r1.ufrrj.br/cpda/dissertacoes-e-teses> \\
\hline UFRB & tem & <https://www.ufrb.edu.br/pgcienciassociais/turma-2015> \\
\hline UFMA & tem & $<$ https://tedebc.ufma.br> \\
\hline UFJF & tem & $<$ https://repositorio.uff.br> \\
\hline UFGD & tem & <https://www.ufgd.edu.br/pos-graduacao/mestrado-sociologia/dissertacoes-defendidas> \\
\hline UFF ANT & tem & <http://ppgantropologia.sites.uff.br> \\
\hline UFF CP & tem & <http://www.uff.br/dcp/?page_id=32> \\
\hline UFF SOC & tem & <http://www.sociologia.uff.br/dissertacao> \\
\hline UFES & tem & $\begin{array}{l}\text { <http://www.cienciassociais.ufes.br/pt-br/pos-graduacao/PGCSdisserta\%C3\%A7\% } \\
\text { C3\%B5es-defendidas> }\end{array}$ \\
\hline UFCG & tem & $<$ http://www.ufcg.edu.br/ $\sim$ ppgcs $>$ \\
\hline UFBA & tem & <http://www.ppgcs.ufba.br> \\
\hline UERJ & tem & $<$ http://www.bdtd.uerj.br> \\
\hline UENF & tem & $\begin{array}{l}\text { <http://uenf.br/posgraduacao/politicas-sociais> e } \\
\text { <http://uenf.br/posgraduacao/sociologia-politica> }\end{array}$ \\
\hline UEM & tem & $<$ http://nou-rau.uem.br/nou-rau/teses_dissertacoes.php> \\
\hline UEL & tem & <http://www.bibliotecadigital.uel.br> \\
\hline UECE & tem & <http://www.uece.br/politicaspublicas> \\
\hline PUC-RIO & tem & $\begin{array}{l}\text { <http://www.cis.puc-rio.br/index.php/posgraduacao/mestradobancodissertacoes> e } \\
<\text { http://www.cis.puc-rio.br/index.php/posgraduacao/doutoradobancoteses> }\end{array}$ \\
\hline
\end{tabular}

